\title{
Have We Learned from Previous Stock Meltdowns?
}

\section{Michel A* and Shaked I}

Questrom School of Business, 595 Commonwealth Avenue, Boston, MA 02215, USA

\begin{abstract}
We have witnessed three major stock market meltdowns over the past three decades. This paper assesses the market shocks of 1987, 1997 and 2008. In particular, we review the history of modern finance and assess whether the role of quantitative finance has developed to reduce the likelihood of future meltdowns. We see that the role of models based on historical price movement often ignore the possibility of fat tails, that risk free arbitrage may exist in normal, but not tumultuous markets and that asset returns and correlations result in extreme values more frequently than predicted by the standard bell curve. Moreover, the desire for outsized returns has driven many money managers to leverage their returns beyond prudent levels, dramatically increasing portfolio risk. In addition, many in Wall Street sell and create new derivative products that are often sold without the necessary due diligence and properly conducted stress tests. The same quantitative courses are taught and similar derivative products are sold as during the three previous meltdowns. Unfortunately, the SEC and academia have taken little permanent action to reduce the odds of further stock meltdowns.
\end{abstract}

Keywords: Derivatives; Illiquidity; Meltdown

\section{Introduction}

It's been seven years since the last financial meltdown. Let's consider the situations that generated the meltdowns of the past 30 years and ask whether markets have changed. Finance is a quantitative discipline. Yet during past twenty years, the mathematics of finance has become so complex and integral to the understanding of financial products that few who buy, sell or create the products of Wall Street understand the ramifications of the assumptions imbedded in the products being sold. An analysis of the role of the quants in the recent history of financial innovation and market meltdowns is illuminating. In particular, a review of the role of derivatives in the meltdowns since 1987 is useful to understand.

\section{Literature Review}

Since the time of Markowitz's early work, quantitative finance has played an important role in portfolio selection, asset pricing, and investment decision-making [1]. Sharpe, Lintner, Fama and others were catalysts in the process of making major inroads into understanding the relationship of securities to market movements and the pricing of securities and portfolio [2-5]. In 1969 Professor Robert Merton introduced stochastic calculus into the financial lexico [6]. Soon afterward, in 1973, Professors Fischer Black and Myron Scholes produced their seminal paper describing the pricing of an option using a differential equation [7]. Thereafter, quantitative finance became a burgeoning discipline. By the end of the last century, Masters and $\mathrm{PhD}$ programs in financial engineering and computational finance were being developed by prestigious schools in the US and Europe. Moreover, physicists graduating from $\mathrm{PhD}$ programs, instead of waiting for tenure track positions to open up in academia, were attracted to Wall Street. They and mathematically oriented finance $\mathrm{PhDs}$ were enticed by both the money and the ability to apply their skills in creating and pricing complex derivative products. Many of the derivatives created had no ready market and were relatively illiquid. Yet the quants were able to develop pricing models for these illiquid securities. Moreover, these derivatives enabled investors to take advantage of market opportunities unavailable prior to the arrival of the quants.

\section{The Long-Term Capital Management Crisis}

But in 1997 the quants hit a bump in the road. Long-Term
Capital Management, a fund fueled by the academic quantitative fire power of Nobel laureates, Merton and Scholes, fell victim to financial shocks in Russia, 5000 miles away from LTCM's tony headquarters in Greenwich, Connecticut. Merton and Scholes had calculated precise odds of losing $5 \%, 10 \%, 15 \%$, and $20 \%$ of its money at Long-Term Capital Management. Roger Lowenstein, a former Wall Street Journal reporter, described money management at LTCM in when genius failed as "less an art" requiring a series of judgments than it was a "science" that could be precisely quantified. He went on to say that the quants at LTCM believed that "only one year in fifty should [the firm] lose at least 20 percent of its portfolio - and the Merton-Scholes encyclical did not entertain the possibility of losing more." Merton's theories assumed that prices would trade in continuous time, namely prices would not have discontinuous jumps arising as a result of panics and where trading in a stock would halt at $\$ 70$ and reopen at $\$ 30$. He also assumed risk free arbitrage, a condition which may exist in ordinary market conditions, but which is unlikely in tumultuous markets. While the models were based on several years of historical data and were right virtually all the time, the killer became known as the fat tails problem.

Fat tails is the description associated with the rate of return distribution of stocks. While traditionally finance models are typically based on a normal curve of returns, Professor Benoit Mandelbrot [8] concluded that the normal distribution did not account for sufficient variance of the returns... In other words, rare events happen more frequently than one would estimate using a normal curve. For example, in describing the 1987 crash of $23 \%$ on Black Monday, Lowenstein [9] indicates that "economists later figured out that, on the basis of the market's historic volatility, had the market been open every day since the creation of the Universe, the odds would still have been against its falling that much on any single day. In fact, had the life of the

${ }^{*}$ Corresponding author: Michel A, Professor, Department of Finance ,Boston University Questrom School of Business, Boston University, Boston, USA, Tel: 617 353-4167; E mail: amichel@bu.edu

Received April 22, 2014; Accepted July 16, 2015; Published July 20, 2015

Citation: Michel A, Shaked I (2015) Have We Learned from Previous Stock Meltdowns? J Glob Econ 3: 151. doi:10.4172/2375-4389.1000151

Copyright: $\odot 2015$ Michel A, et al. This is an open-access article distributed under the terms of the Creative Commons Attribution License, which permits unrestricted use, distribution, and reproduction in any medium, provided the original author and source are credited. 
Universe been repeated one billion times, such a crash would have still been theoretically "unlikely". But even with the economic hindsight of quantitative economists, the crash of ' 87 did occur. So with this knowledge that historical data may prove unreliable in building models to price assets, LTCM went on to use historical data to build its models, assuming returns were independently distributed and negatively correlated from one period to the next. Moreover, the markets were getting more liquid with more volume which meant the markets were more efficient and more "continuous", an important attribute of Merton's continuous time modeling. The possibility that trades would collapse together was remote. According to Lowenstein [9], the quants suggest that "the figures implied that it take a ten-sigma event - that is, a statistical freak occurring one in every ten to the twenty-fourth power times - for the firm to lose all of its capital within one year." The mathematicians at LTCM were so confident of their risk assessment that when discrepancies between current prices and historical prices occurred, they exploited those differences by using massive amounts of leverage, betting that prices would return to their historical norms. While every first year finance student understands the risks associated with overleveraging, the quants wanted to take advantage of any market anomaly. Debt piled up while the quants waited for the markets to return to normal. But they didn't. In each of the asset classes in which LTCM invested, movement became highly correlated, rather than remaining independent. All of the quants' trades were hemorrhaging simultaneously. The professors forgot the lesson of '87, that fat tails can kill you. In panic mode, traders and the securities that they trade don't necessarily move independently, but often move together, driven by fear and greed. At LTCM any default on any of its seven thousand derivative contracts, according to Lowenstein [9], would cause a cross default on ALL others, covering a notional value of $\$ 1.4$ trillion. The government had to intercede to save the country's financial system, since such a massive default would have caused defaults by many of the firm's counterparties - often the nation's largest financial institutions. The quants forgot the lesson of 1987, that fat tails can do you in, and forgot a lesson learned by every student in Finance 101; too much debt can also do you in. We now had two thousand year market meltdowns within the span of ten years.

\section{The Mortgage Meltdown of 2008}

Another ten years or so passed and we had a third thousand-year market meltdown. The housing market started to collapse in 2007. It disintegrated in 2008. By now the quants had forgotten about the missteps of the previous meltdowns. They believed that with more sophisticated and complex models, the meltdowns could be a thing of the past. Increasing in popularity were asset-backed securities such as the Collateralized Debt Obligation, in which banks buy subprime mortgages and bundle them into a single instrument. The resulting $\mathrm{CDO}$ is then divided into tranches, each representing a claim on the underlying securities, with the highest tranche supposedly the most secure and the lowest tranche often considered equity or toxic waste. Yet investors were assured that they could buy default insurance on the equity tranche. It looked like the purchases of both the risky and safe tranches would be winners through the derivative product that was created to insure against loss. Lehman Brothers, Merrill Lynch, Morgan Stanley and others integrated vertically by buying mortgage providers. Demand for mortgages increased and hedge funds soon entered the $\mathrm{CDO}$ market. Yet the market was not actively traded because the securities were so complex and difficult to value. Thus, billions of retirees' dollars were invested in complex securities that were virtually impossible to value. The CDOs were generally bought at a negotiated rather than a market price, which meant there was uncertainty as to their value. Moreover, the hedge funds used significant debt to make their purchases. The credit derivative market burgeoned to over $\$ 60$ trillion with David Li's mathematical innovation in 2000 of the Gaussian Copula [10]. This development enabled the quants to compute the time to default using asset correlations and probabilities of default. But like the quants at LTCM, they failed to recognize that the risk factors exhibit fat tails and that the asset returns and correlations result in extreme values more frequently than predicted by the standard bell curve. While academics and many Wall Street quants blindly trusted the model, the essence of the fat tails and the consequences of significant leverage caused many of the model's users to be blindsided by significant losses. Once again, the quants were tripped up by the complexity of their models and the assumptions driving them. This time the impact of credit derivatives spilled over to the stock and bond markets. The Dow plunged approximately $40 \%$, the debt markets were frozen, and muni yields increased more than 30\%. Again the quants precipitated another thousand-year meltdown.

\section{Conclusions}

While there were many parties culpable in this dramatic downturn, including bankers, credit rating agencies, mortgage brokers, hedge funds and others, without the blind acceptance of the quant models it is doubtful whether the worst stock market disaster since the great depression would have occurred. Yet after the third market collapse in 20 years driven by the quants, quantitative finance is still valued by business schools throughout the country. Those writing books and papers about derivatives create more complex and sophisticated models. The understanding of this mathematical literature, namely the progeny of Merton's stochastic calculus, has become the holy grail of many quants. Business schools and finance departments would be better off encouraging Ph.D. students to develop models which are intelligible by all who use them, not merely the mathematicians and physicists who create them. Moreover, many of the PhDs in academia train MBAs that are recruited by Wall Street and who then invest retirees' money using models that are mathematically elegant, but not valid in the real world. We would all benefit from business schools emphasizing a better understanding of markets and securities as well as the necessary due diligence which should be associated with all new products brought to market.

Similarly, those in industry who sell and create new derivative products continue to be actively sought. Yet these products are often sold without the necessary due diligence and properly conducted stress tests. While stress tests may be performed, they are often performed inadequately because of the lack of understanding of the nature and complexity of the derivative products created. They miss the fat tails tests because such tests are virtually impossible. There is little to guide us about how far out on the tails the event will be. Stress tests use past data, but that's exactly the problem with derivatives created using the tractable, but inappropriate Gaussian distribution of events. As Fidelity says in their ads, "past performance is no guarantee of future results." Yet the temptation to generate hundreds of millions of dollars of profit has blinded the many sellers of these derivative products.

For the world to be subjected to a thousand year meltdown every ten years is too much. Let's learn from the past. Little has been learned from the previous crises. Leverage and fat tails have generated each of these meltdowns. Little has changed in academia or Wall Street since the meltdowns of 1987 or 2008. Business school deans should be setting direction for their schools and their finance departments. Wall Street 
leaders should think more responsibly. It's time for a new direction.

\section{References}

1. Markowitz HM (1952) Portfolio selection. The Journal of Finance 7: 77-91.

2. William FS (1964) Capital Asset Prices - A Theory of Market Equilibrium Under Conditions of Risk. Journal of Finance 19: 425-442.

3. John $L$ (1965) The valuation of risk assets and the selection of risky investments in stock portfolios and capital budgets. Review of Economics and Statistics 47 13-37.

4. Eugene FF (1968) Risk, Return and Equilibrium: Some Clarifying Comments. Journal of Finance 23: 29-40.
5. Eugene FF (1970) Efficient Capital Markets: A Review of Theory and Empirical Work. The Journal of Finance 25: 383-417.

6. Merton RC (1969) Lifetime Portfolio Selection under Uncertainty: the Continuous-Time Case. The Review of Economics and Statistics 51: 247-257.

7. Fischer B, Scholes M (1973) The Pricing of Options and Corporate Liabilities. Journal of Political Economy 81: 637-654.

8. Mandelbrot B (1963) The Variation Of Certain Speculative Prices. Journal of Business 36: 394-419.

9. Lowenstein R (2000) When Genius Failed: The Rise and Fall of Long-Term Capital Management. Random House.

10. David L (2000) On Default Correlation: A Copula Function Approach. Journal of Fixed Income 9: 43-54 